\title{
SMART WATER PUMP
}

\author{
Aditya Pawar \\ Department of Information- \\ Technology \\ Shah \& Anchor Kutchhi \\ Engineering College, \\ Mumbai, Maharashtra India
}

\author{
Jeet Raithatha \\ Department of Information- \\ Technology, \\ Shah \& Anchor Kutchhi Engineering \\ College, \\ Mumbai, Maharashtra India \\ Manish Belande \\ Department of Information \\ Technology \\ Shah \& Anchor Kutchhi Engineering \\ college \\ Mumbai, Maharashtra India
}

\author{
Shruti Patel \\ Department of Information- \\ Technology \\ Shah \& Anchor Kutchhi \\ Engineering College, \\ Mumbai, Maharashtra India
}

\begin{abstract}
With water being one of the many important natural resources. Seldom, for regular use water is wasted on a large quantity. Causing water shortage. Making, it imperative to handle water responsibly. Since, water is wasted because surplus flow of water into storage units. Monitoring Level of water becomes crucial. Water being stored into storage tanks of factories; it becomes important to monitor the level of water that flows inside the storage unit and the amount of water that moves out. As water decides the overall heath of the bio-diversity around us. With this system proposal we want to focus on water level and quality monitoring.
\end{abstract}

Keywords - Water level, Ultrasonic Proximity sensor, Turbidity, Smart Water Pump.

\section{INTRODUCTION}

As every one can agree upon, that water is an important element in everyone's lives. Everyone's routine includes usage of water. The most basic need to survive, everyone's day start with water. It is observed that general households use overhead tanks as a preventive measure from various stuff. To protect it from pest infestation to surplus growth of algae. In these tanks, the stored level of water is however not monitored leading to people forgetting to turn the motor off which pumps the water. This inevitably wastes water and the root cause to water shortage. Hence, it becomes crucial for us to mitigate these issues and find a solution which can prevent the motor from keep on flowing water. With the applications of this project in several avenues such as Tidal studies, Surface water monitoring, River level monitoring, etc. The main goal of this paper is to review water level and its quality.

\section{REVIEW OF LITERATURE}

In an analytical have a look at carried out with the aid of using the Delhi Committee of the Associated Chambers of Commerce and Industry of India (ASSOCHAM), it's been discovered that there was a widespread increase within side the wastage of water because of severe reasons. According to ASSOCHAM, the proportion of water wasted has been multiplied to an alarming $40 \%$ compared to the preceding year. On February 11, 2018 the British Broadcasting Corporation (BBC) positioned Bengaluru on a listing of eleven essential towns in the contemporary-day generation having most water associated problems. The BBC blames a spike in population boom and new assets developments, Bengaluru's conflict to control its water and sewage systems, and a huge waste of consuming water because of negative plumbing. Also, many villages withinside the indoors of Maharashtra and lots of different states are going through essential water scarcity because of drought and water deliver mismanagement. Our device is an initiative to assist shrink or as a minimum lessen those water wastage and shortage problems at some point of the nation.

\section{CIRCUIT AND COMPONENTS}

To automate the method, we've created a complex circuit to keep away from any failure of the system. We have used Ultrasonic Proximity sensor as a number one decider whether or not to permit water flow or not that is similarly depending on the turbidity detector that detects the quality of the water. This method of every sensor depending on different sensor to intelligently make choice primarily based totally on it's surrounding, adds a further protection layer, through doing so we similarly enhance the performance of the system, and its 


\section{International Journal of Engineering Applied Sciences and Technology, 2021 \\ Vol. 5, Issue 12, ISSN No. 2455-2143, Pages 166-168 \\ Published Online April 2021 in IJEAST (http://www.ijeast.com)}

versatility to preserve changing in line with its surrounding. Designing such tricky circuit and providing software program to seamlessly adapt to surroundings is finished here.

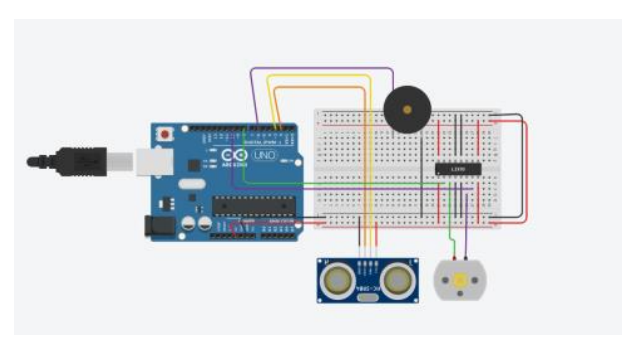

FIg.1 Circuit diagram of the system

\section{A. Ultrasonic Proximity sensor:}

Ultrasonic Proximity sensor is a very useful and effective sensor to measure the distance to an object. The simplicity it offers provides an amazing output. From 2 centimeters to 400 centimeters, or 1 inch to 13 feet. Sharp rangefinders are impaired by sunlight and black content, but this one isn't. Ultrasonic sensor is the primary decider whether the motor will open or close this is done by monitoring the water level Ultrasonic sensor will trigger the motor to run when it detects water is below the minimum level and starts the flow of water. As soon as water reaches the maximum point the motor stops the flow of water.

\section{B. Turbidity Sensor:}

The quality of water can be detected by using a unique sensor such as the turbidity sensor. The turbidity sensor detects the purity of water or the quality of water by measuring the impurities in the liquid. This is called as the total suspended solids. Whenever there is an increase in these solids, the sensor detects this as impurities and shows the user. You can adjust the range of the turbidity sensor to a specific limit. This sensor can be used in various places where liquid quality is of utmost importance. In our project we use this to check the quality of the water.

\section{Arduino Uno:}

Uno is a microcontroller board developed by Arduino.cc which is an open-source electronics platform mainly based on AVR microcontroller Atmega328. It is a unique microcontroller which acts as $\mathrm{n}$ 8-bit ATmega328P microcontroller. The Arduino Uno comes with USB interface, 6 analog input pins, $14 \mathrm{I} / \mathrm{O}$ digital ports that are used to connect with external electronic circuits. Out of $14 \mathrm{I} / \mathrm{O}$ ports, 6 pins can be used for PWM output. It allows the designers to control and sense the external electronic devices in the real world. It is an open-source platform, means the boards and software are readily available and anyone can modify and optimize the boards for better functionality. The software used for Arduino devices is called IDE (Integrated Development Environment) which is free to use and required some basic skills to learn it. It can be programmed using $\mathrm{C}$ and $\mathrm{C}++$ language.

\section{Piezo Sensor:}

Piezoelectric transducers are electroacoustic transducers that convert strain or mechanical pressure into an alternating electric power. It's used to calculate physical portions that aren't strictly measurable, consisting of force, strain, tension, and so on. When water is flowing or not a legitimate alarm is located so it is able to warn the user that the system has completed its process and the tank is full

\section{E. DC motor:}

A direct current or DC motor, converts electrical energy into mechanical energy. It is one of two basic types of motors: the other type is the alternating current or AC motor. Among DC motors, there are shunt-wound, series-wound, compoundwound and permanent magnet motors. A DC motor consists of a stator, an armature, a rotor and a commutator with brushes. Opposite polarity between the two magnetic fields inside the motor cause it to turn. DC motors are the simplest type of motor and are used in household appliances, such as electric razors, and in electric windows in cars.

\section{CONNECTIONS AND WORKING}

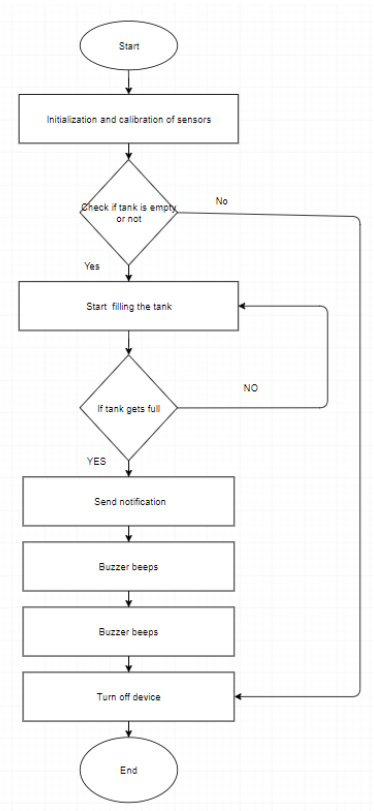

Fig.2 Flowchart of the System 


\section{International Journal of Engineering Applied Sciences and Technology, 2021 \\ Vol. 5, Issue 12, ISSN No. 2455-2143, Pages 166-168 \\ Published Online April 2021 in IJEAST (http://www.ijeast.com)}

\section{CONCLUSION}

As we can see the project can reduce the incessant wastage of water and it can be seen that water can be saved on a large scale. The projects also display unique and correct results. As the whole process is automated it can be seen that, with the introduction of technology there won't be a need for human intervention, hence keeping the error rate of human mistakes to a minimum. With the use of wide range of sensors, it can be observed that water which is pumped is clear and not wasted. Which is done swiftly without and error and accurately. As these sensors are cost effective it can perform as a to have gadget which can be hooked up in rural areas where the problem lies predominately.

\section{REFERENCES}

[1] https://www.thehindu.com/todayspaper/tpnational/tp-newdelhi/Now-penaltieson consumers for-overflowingtanks/article16020198.ece

[2] Shandong Jianzhu "Design of intrinsically safe intelligent water-level monitor used in coal mine ", IEEE Trans. on Industrial Applications, vol. 19, pp.1052 -1056 1983Byron Francis (2016),

[3] Arduino: The Complete Beginner's Guide, CreateSpace Independent Publishing Platform.

[4] Getting Started with Arduino UNO, https://www.arduino.cc/en/Guide/ArduinoUno

[5] Rapelli Navin, Myakal Ashish, Kota Vyankatesh, Rajarapollu Prachi R. (2019). "IOT Based Smart Water Management Monitoring and Distribution System for an Apartment", Intelligent Computing and Control Systems (ICCS) 2019 International Conference on, pp. 440-443, 2019.

[6] S.M. Saifur Rahman Faisal, Iftekhar Uddin Ahmed, Humayun Rashid, Remon Das, Md. Mobarak Karim, S M Taslim Reza. (2017). "Design and Development of an Autonomous Floodgate using Arduino Uno and Motor Driver Controller" Proceedings of the 2017 4th International Conference on Advances in Electrical Engineering pp 28-30 September, 2017, Dhaka, Bangladesh.

[7] Siddula Sai Sreekar, Jain P.C., Upadhayay Madhur Deo. "Real Time Monitoring and Controlling of Water Level in Dams using IoT" 201*IEEE 8th International Advance Computing Conference (IACC). pp.87-91

[8] Puig V, Ocampo-Martinez C, Romera J, Quevedo J, Negenborn R, Rodriguez $\mathrm{P}$ and de Campos $\mathrm{S}$.
(2012). "Model predictive control of combined irrigation and water supply systems: Application to the Guadiana river", Proceedings of 2012 9th IEEE International Conference on Networking, Sensing and Control, pp. 85 - 90, 2012.

[9] Litrico X. (2002). "Robust IMC flow control of SIMO dam-river open-channel systems", IEEE Transactions on Control Systems Technology, vol. 10,no. 3, pp. 432-437, 2002

[10] Guo J and Chen Q. (2010). "An Application of Fuzzy Control Based on PLC in Rubber Dam Monitoring System", 2010 International Conference on System Science, Engineering Design and Manufacturing Informatization, vol. 2, pp. 266 - 269, 2010

[11] Inyiama H. C. and Obota M. E., "Designing Flood Control Systems Using Wireless Sensor Networks", Intern pp. 12-15

[12] Nandaniya M. (2013). "A Review Paper of Automatic Canal Gate Control of Induction Motor with PLC and VFD, Powered by Solar System and Monitoring by SCADA", International Journal of Emerging Trends in Electrical and Electronics (IJETEE), vol. 1, no. 1, pp. 32-39, 2013.

[13] Iyer $M$, Pai S, Badri $S$ and Kharche $S$. (2013). "Embedded Dam Gate Control System using ' $\mathrm{C}$ ' and Visual Basic", International Journal of Computer Applications (0975 - 8887), vol. 69, no. 2, pp. 32-37, 2013.

[14] S. Md. Umar Talha, Mohani S. Sheraz, S. Hassan Ahmed and M. Ebrahim, (2012) "Design for an Irrigation and Monitoring System of an Automated Dam", Proceedings of the International MultiConference of Engineers and Computer Scientists, vol. 2, pp. 65-67, 2012.

[15] Sathya V, Arun Kshitij, Mahajan Harshitaa, Kumar Singh Amit. (2019) "Automate the Functioning of Dams Using IoT" 2019 3rd International Conference on Computing Methodologies and Communication (ICCMC) pp. 71-75

[16] Dr. Shivappa Nagesha, Rao Aishwarya S, T Aishwarya, Athreya Jahnavi S, H Mandakini. (2020). Dam Automation using IoT, INTERNATIONAL JOURNAL OF ENGINEERING RESEARCH \& TECHNOLOGY (IJERT) Volume 09, Issue 05 pp. 68-71 (May 2020) 